\title{
Finite-Element Limit Analysis for Solid Modeling of Reinforced Concrete
}

\author{
Andersen, Mads Emil Møller; Poulsen, Peter Noe; Olesen, John Forbes
}

Published in:

Journal of Structural Engineering

Link to article, DOI:

10.1061/(ASCE)ST.1943-541X.0002979

Publication date:

2021

Document Version

Peer reviewed version

Link back to DTU Orbit

Citation (APA):

Andersen, M. E. M., Poulsen, P. N., \& Olesen, J. F. (2021). Finite-Element Limit Analysis for Solid Modeling of Reinforced Concrete. Journal of Structural Engineering, 147(5), [04021051].

https://doi.org/10.1061/(ASCE)ST.1943-541X.0002979

\section{General rights}

Copyright and moral rights for the publications made accessible in the public portal are retained by the authors and/or other copyright owners and it is a condition of accessing publications that users recognise and abide by the legal requirements associated with these rights.

- Users may download and print one copy of any publication from the public portal for the purpose of private study or research.

- You may not further distribute the material or use it for any profit-making activity or commercial gain

- You may freely distribute the URL identifying the publication in the public portal

If you believe that this document breaches copyright please contact us providing details, and we will remove access to the work immediately and investigate your claim. 


\title{
FINITE ELEMENT LIMIT ANALYSIS FOR SOLID MODELING OF REINFORCED CONCRETE
}

\author{
Mads Emil Møller Andersen ${ }^{1}$, Peter Noe Poulsen ${ }^{2}$, and John Forbes Olesen ${ }^{3}$ \\ ${ }^{1}$ Ph.D. Student. COWI A/S, Parallelvej 2, Kongens Lyngby, Denmark. Email: \\ mean@cowi.com \\ ${ }^{2}$ Associate Professor. Department of Civil Engineering, Technical University of \\ Denmark, Brovej 118, Kongens Lyngby, Denmark \\ ${ }^{3}$ Associate Professor. Department of Civil Engineering, Technical University of \\ Denmark, Brovej 118, Kongens Lyngby, Denmark
}

\begin{abstract}
Complex triaxial stress states are present in many reinforced concrete structures. These structures are often analyzed using simple hand calculations based on methods designed for plane structures. However, this can result in designs that are inefficient and excessive in material usage. This paper introduces Finite Element Limit Analysis (FELA) for modeling of reinforced concrete structures, with separate modeling of concrete and reinforcement in a so far unseen scale. The method provides results for the capacity as well as the stress state and failure mechanism in the ultimate limit state. The FELA framework uses solid elements together with the Modified Mohr-Coulomb and von Mises yield criteria. The framework uses a computationally inexpensive tetrahedral FELA element, which makes it possible to model rebar details in 3D with adequate discretization. The framework is demonstrated in two examples. One for verification and one showing the practical use of the framework by analyzing a tension connection with overlapping U-bars. The numerical results are compared to the failure mechanism and capacity from experiments.
\end{abstract}

\section{INTRODUCTION}

Reinforced concrete is a composite material consisting of reinforcement bars embedded in concrete. The design of reinforced concrete can, to a large degree, be simplified using assumptions of plane stress or plane strain. However, for massive concrete structures and rebar detailing in, for example, connections between beams and columns or slabs and walls, this assumption does not hold. To properly understand how these structures carry load and how they collapse, solid modeling with triaxial stress 
states is required. Currently, these structural members are designed based on codes and guidelines, but naturally, codes and guidelines cannot describe detailing arising from all possible structural problems. This paper presents a novel approach for solid modeling of reinforced concrete in the ultimate limit state with complex triaxial stress states, where reinforcement bars are considered as discrete components.

Currently, limit analysis using hand calculations, based on idealized and simplified models, is the norm when validating reinforcement detailing. The methods are based on the lower and upper bound theorems, as first suggested by Gvozdev (1960) and independently by Drucker et al. (1952). However, before the theorems were formally written down, methods based on the ideas had already been developed by researchers and engineers. These methods were based on a thorough understanding of the structures rather than on a strict mathematical formulation. Examples of these methods include the truss model by Mörsch (1922) (now called the strut-and-tie method (Schlaich et al. 1987)), the stringer method by Lundgren (1949), the strip method by Hillerborg (1974) which are all lower bound methods, and the yield-line method by Johansen (1943, 1962), which is an upper bound method. The design of reinforcement details is primarily based on the strut-and-tie method and on failure mechanisms.

Design and validation of reinforced concrete details can also be performed by using advanced non-linear stiffness based methods. These methods use advanced constitutive elasto-plastic models to capture the behaviour of structures subject to loading. The calculations are iterative and the stepping is usually based on either load or deformation. This provides detailed results about the behaviour of the structures al the way to collapse as well as the limit load. Vecchio and Selby (1991) promoted this type of modelling for structures with triaxial stress states, and since then research has been on going. Recent results by Gimeno (2017) show modeling of reinforced concrete with discrete modeling of reinforcement for an anchorage block. Also general purpose FEM program exist which can do thus type of calculations, e.g. ATENA (Červenka and Červenka 2017) and DIANA (Ferreira 2020). Common for these methods and programs is that they are very powerful, however, they require a lot of additional physical parameters which are difficult to access. Finite Element Limit Analysis (FELA) differs from these approaches by being based on a rigid-plastic material model, i.e., the model is based on stress equilibrium and not on a deformation/stiffness based approach. This means that only information about the limit state is provided by the analysis, however, it also means that the material models simplify to the modelling of yield surfaces, which are usually well defined by only a few material parameters.

FELA, which utilizes either the principle of the upper or lower bound theorem for rigid-plasticity in a numerical framework, has reached a mature state for plane stress reinforced concrete structures. The method was first proposed by Anderheggen and Knöpfel (1972) and has since developed into an active field of research. Plane structures subject to in-plane forces where treated by Poulsen and Damkilde (2000), which presented a framework for modeling reinforced concrete structures. The framework made use of a triangular element in conjunction with a bar and a beam element and also facilitated material optimization. Further work by Larsen (2010), and Herfelt (2017) has made the method commercially viable, and the first commercial program for verification of reinforced concrete structures subjected to in-plane forces was launched in 
2019 (Herfelt et al. 2019).

FELA, with solid modeling, using the Mohr-Coulomb yield criterion, was introduced by Martin and Makrodimopoulos (2008). Martin and Makrodimopoulos used semidefinite convex optimization to model the Mohr-Coulomb criterion. Larsen et al. (2009) extended the approach to include smeared reinforcement by using additional linear constraints. Characteristic of the two studies was that the underlying optimization algorithms and the available hardware were not sufficient to provide detailed analysis. Recently work by Vincent et al. (2018) has shown examples of large scale modeling of a pier head indicating a possible shift in this respect. Very few studies have made attempts at modeling concrete and steel separately, with the examples being simple. A typical example is the pullout of a reinforcement rod embedded in concrete (Herfelt 2017).

A fine mesh discretization is required in order to model, in detail, the state of stress in reinforced concrete structures at the ultimate limit state. The present work aims at giving a detailed account of the stress state in both concrete and reinforcing steel which are modelled as separate parts. Therefore, it takes a large number of elements to model even small parts of a structure, to study the local effects of reinforcement detailing. Thus, it is crucial to allow for the largest possible number of elements, by applying a very simple solid element, namely, the four node tetrahedral element with a constant stress field. This is done although the element is known to perform badly in other circumstances, e.g. exhibiting volumetric locking when applied as a displacement compatible element in cases of zero, or near to zero, dilatation. In the present FELA setting the element is based on the mixed-formulation (Borges et al. 1996; Herfelt 2017), meaning that the requirement of stress equilibrium along element surfaces was relaxed, and instead, equilibrium was enforced in corner nodes. The mixed-formulation was used to eliminate the problem of locking and has also been shown to enhance mesh convergence, as reported by Krabbenhøft et al. (2007a, 2007) and Herfelt (2017). The element may produce spurious hydrostatic stress states which may corrupt the solution (Andersen and Koch 2018). However, in the present application, reinforcing steel primarily experiences uniaxial stresses, and concrete hydrostatic stresses are limited by the low tensile capacity. Therefore, a limitation on the magnitude of the hydrostatic stress component for steel is introduced, which is demonstrated to eliminate the spurious states of stress, and the element is demonstrated to produce reliable results for structural entities in so far unseen detail.

This study sets out to investigate the usefulness of FELA to determine the capacity of reinforced concrete with discrete modeling of rebar details. The perspective being, the enhanced ability of the engineer to design complicated reinforcement details with adequate capacity. As a case study, a connection detail between two precast concrete slabs using overlapping U-bars is analyzed. The connection has been the subject of an experimental study by Jørgensen and Hoang (2013). The experimental series was designed to produce failure primarily in the concrete core. For this reason, the concrete effectiveness factor is important for the calibration of the model, and the experimental results are used to give an estimate of this parameter. Furthermore, the resulting failure mechanisms from the numerical calculations are compared to the experimental findings. 


\section{FINITE ELEMENT LIMIT ANALYSIS FOR SOLIDS}

Finite Element Limit Analysis (FELA) is a combination of the domain discretization of the finite element method and rigid-plastic limit analysis. The method was first proposed by Anderheggen and Knöpfel (1972). FELA is based on the extremum principals (Gvozdev 1960; Drucker et al. 1952), which is also the case for hand calculations based on the rigid plastic material model. The method can be based on either the upper or lower bound theorem. If the analysis is based on the upper bound theorem, the elements describe a kinematically admissible state of collapse, and if the lower bound theorem is used, the elements describe a statically admissible stress field.

The FELA implementation described in this paper is based on the lower bound theorem. The variables of the elements are stresses, and equilibrium between elements is enforced through stresses on the element surfaces. The equilibrium can be described through a matrix-vector product $\mathbf{H} \boldsymbol{\sigma}$, where $\boldsymbol{\sigma}$ is a vector containing the stress variables of the elements, and $\mathbf{H}$ is the so-called equilibrium matrix. The equilibrium matrix has contributions from each individual element. The element equilibrium matrix, $\mathbf{h}_{e l}$, is described later. The stresses of the elements must also obey the limitations prescribed by the yield conditions of the materials. The limitation of the material model is ensured in the stress points of the element by the inequality $f_{i}\left(\sigma_{i}\right) \leq 0$ for $i=1, \ldots, n$ where $f_{i}$ is the yield surface and $\sigma_{i}$ is the stress state for the $i$-th stress point, which is enforced in all $n$ stress points. With equilibrium established and the stress of the elements limited by a yield function, the loading in the model can be optimized. The optimization problem may then be formulated as:

$$
\begin{array}{ll}
\operatorname{maximize} & \lambda \\
\text { subject to } & \mathbf{H} \boldsymbol{\sigma}=\mathbf{R} \lambda+\mathbf{R}_{0} \\
& f_{i}\left(\boldsymbol{\sigma}_{i}\right) \leq 0, \quad i=1, \ldots, n
\end{array}
$$

where the loading terms, $\mathbf{R}$ and $\mathbf{R}_{0}$, are introduced for scalable and constant loads, respectively. Also the load factor, $\lambda$, is introduced, which is the optimization parameter. In this case, the optimization is a maximization, since the implementation is based on the lower bound theorem. The optimal solution is the maximum lower bound solution.

In the present work, the yield surfaces are either described by the Modified MohrCoulomb yield criterion using semidefinite programming (Martin and Makrodimopoulos 2008; Krabbenhøft et al. 2007a; Bisbos and Pardalos 2007; Krabbenhøft et al. 2007b), or von Mises yield criterion using second-order cone programming (Bisbos et al. 2005; Makrodimopoulos and Martin 2006). When implementing yield surfaces defined by either of these methods, additional linear equations and auxiliary variables, $\alpha$, are needed. These are described later in this paper, together with the final form of the optimization problem.

\section{CONSTANT STRESS TETRAHEDRON}

Solid finite element limit analysis can be a computationally demanding task, due to the nature of optimization and generally large problem sizes for 3D meshes, and especially for the purposes it is utilized in the paper. For these reasons, a simple and computationally inexpensive element with a constant triaxial stress state is used. The 
element is shown on Fig. 1, with the normal vector of Surface 1 shown, as well as the force components of Node 1 . The following stress vector specifies the triaxial stress state of the element:

$$
\boldsymbol{\sigma}_{\mathrm{el}}^{\top}=\left[\begin{array}{llllll}
\sigma_{x x} & \sigma_{y y} & \sigma_{z z} & \sigma_{x y} & \sigma_{x z} & \sigma_{z y}
\end{array}\right]
$$

The element, in the shape of a tetrahedron, is well suited for modeling complex geometries. The element contains one stress point and thus describes a constant stress state. In the strict lower bound formulation, inter-element equilibrium needs to be ensured on element surfaces. However, applying an element with a constant triaxial stress state, the resulting stress state would lock. The locking happens because the surface stress equilibrium requires 6 equations for the element. Each surface requires one equation for normal equilibrium and two for shear equilibrium, this amounts to a total of 12 equations for the element. However, since each surface in the interior is shared by two elements the number of equations can be divided by two, yielding an average close to 6 equations required for surface stress equilibrium. With six stress variables per element this yields a determinate system of linear equations, i.e., there are no free parameters to optimize.

Instead of enforcing surface stress continuity directly between adjoining elements, force equilibrium is enforced in the corner nodes of the elements. The modified element has the same amount of equations per element ( 3 equations in 4 nodes); however, in average the equations are now shared by more than 2 elements. This yields an indeterminate system of equation, which removes the problem of locking. The modification is statically equivalent to the original problem. However, equilibrium is now enforced in an average sense, which is a relaxation of the strict lower bound requirements. With the relaxation the element is based on a so-called mixed formulation. Elements of the mixed formulation type interpolate stresses with shape functions. The contribution from stresses on an element surface to the nodal forces are then found from the integration over the surface area, $A_{s}$ :

$$
\mathbf{q}_{s}=\int_{A_{s}} \mathbf{N}_{s}^{\top} \mathbf{t}_{s} \mathrm{~d} A_{s}
$$

where $\mathbf{q}_{s}$ is the contribution from surface $s$ to the nodal forces, $\mathbf{N}_{s}$ is a linear interpolation matrix on the surface, and $\mathbf{t}_{s}$ is the surface stress vector. Equation (3) is the general formulation, for the present formulation this simplifies into an even distribution into the three corner nodes. For elements of the mixed formulation, it is not known in advance, whether the failure load will converge from above or below with increased

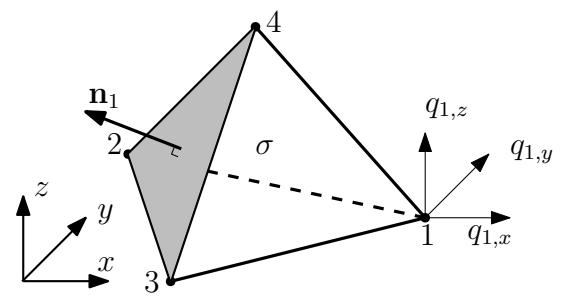

Fig. 1. Constant stress tetrahedron. 
mesh discretization. Examples show that for the present formulation, the failure load converges from above. This means that the load carrying capacity is overestimated until the failure load is converged.

The relaxation described above has the unfortunate effect that spurious modes of equilibrium are possible for material models without hydro-static stress limitations, which is the case for the von Mises yield criterion. The problem is overcome by a slight modification of the implementation of the von Mises yield criterion, which is described later. The relaxation does not pose any problem for the Modified Mohr-Coulomb yield criterion due to the limited tensile strength.

\section{Equilibrium matrix}

In the present formulation the equilibrium matrix transforms the stress state of the element into equivalent forces in the corner nodes. This is done by first computing the stresses on the element surface and then distributing it equally into each of the three corner nodes. The stresses, $\mathbf{t}_{s}$, for Surface $s$ is found from the relation: $\mathbf{t}_{s}=\boldsymbol{\sigma} \mathbf{n}_{s}$, where $\boldsymbol{\sigma}$ is the Cauchy stress tensor and $\mathbf{n}_{s}$ is the unit normal vector of the surface. The transformation to the desired stress vector notation presented in (2), can be performed by introducing the stress equality:

$$
\boldsymbol{\sigma} \mathbf{n}_{s}=\mathbf{P}_{s} \boldsymbol{\sigma}_{\mathrm{el}}, \quad \mathbf{P}_{s}=\left[\begin{array}{cccccc}
n_{s, x} & 0 & 0 & n_{s, y} & n_{s, z} & 0 \\
0 & n_{s, y} & 0 & n_{s, x} & 0 & n_{s, z} \\
0 & 0 & n_{s, z} & 0 & n_{s, x} & n_{s, y}
\end{array}\right]
$$

where $\mathbf{P}_{s}$ is the element stress to surface stress matrix. Since the stress on each surface is constant, due to the constant stress field, the contribution to the equilibrium force in the corner nodes is a third of the total force on the surface, see (3). The total stress to nodal force matrix, $\hat{\mathbf{P}}_{s}$, is then given by:

$$
\mathbf{q}_{i, s}=\frac{A_{s}}{3} \mathbf{P}_{s} \sigma_{\mathrm{el}}=\hat{\mathbf{P}}_{s} \sigma_{\mathrm{el}}
$$

where $\mathbf{q}_{i, s}$ is the force vector of Node $i$ from Surface $s$ and $A_{s}$ is the surface area of surface $s$. Each element surface contributes to the nodal forces in its corner nodes. With the surfaces enumerated by the opposing node, the equilibrium for the entire element is ensured by:

$$
\mathbf{q}_{\mathrm{el}}=\left[\begin{array}{c}
\hat{\mathbf{P}}_{2}+\hat{\mathbf{P}}_{3}+\hat{\mathbf{P}}_{4} \\
\hat{\mathbf{P}}_{1}+\hat{\mathbf{P}}_{3}+\hat{\mathbf{P}}_{4} \\
\hat{\mathbf{P}}_{1}+\hat{\mathbf{P}}_{2}+\hat{\mathbf{P}}_{4} \\
\hat{\mathbf{P}}_{1}+\hat{\mathbf{P}}_{2}+\hat{\mathbf{P}}_{3}
\end{array}\right] \sigma_{\mathrm{el}}=\mathbf{h}_{\mathrm{el}} \sigma_{\mathrm{el}}
$$

where the element equilibrium matrix, $\mathbf{h}_{\mathrm{el}}$, is defined implicitly.

\section{YIELD CONDITIONS OF THE MATERIALS}

In the FELA framework, the material models are defined by yield surfaces. The Modified Mohr-Coulomb and von Mises yield surface are used for concrete and steel, respectively. The Modified Mohr-Coulomb yield criterion requires the use of semidefinite programming, since the yield criterion cannot be written using the general stress 
parameters in the triaxial stress state, but requires the use of principal stresses. This is not the case for the von Mises criterion, which is why the computationally cheaper method of second-order cone programming (Boyd and Vandenberghe 2004) can be used. The implementations of the yield surfaces are described in the following.

\section{Modified Mohr-Coulomb yield criterion for concrete}

The Modified Mohr-Coulomb yield criterion has a friction and a separation yield criteria expressed by the following formulas:

$$
\begin{aligned}
\sigma_{1} & \leq f_{t} \\
k \sigma_{1}-\sigma_{3} & \leq f_{c}
\end{aligned}
$$

where $\sigma_{1} \geq \sigma_{2} \geq \sigma_{3}$ are the principal stresses, $f_{t}$ is the concrete tensile strength, $f_{c}$ is the concrete compressive strength and $k$ is the frictional parameter, which for concrete is usually taken as $k=4$ (Nielsen and Hoang 2011).

When a rigid-plastic material model is used for concrete, which is an approximation of the real material behavior, the strength needs to be reduced. The reduction is made by the so-called concrete effectiveness factors in the following way (Nielsen and Hoang 2011):

$$
\begin{aligned}
f_{c, \mathrm{eff}} & =v f_{c} \\
f_{t, \mathrm{eff}} & =v_{t} f_{t}
\end{aligned}
$$

where $v$ and $v_{t}$ are the effectiveness factors on the compressive and tensile strengths, respectively. These factors are case specific and are based on empirical results.

Larsen (2010) showed (based on work by Martin and Makrodimopoulos (2008), Krabbenhøft et al. (2007a) and Bisbos and Pardalos (2007)) that the criterion (7) can be cast as two semi-definite constraints, and two inequalities by use of two auxiliary variables, $\alpha_{1}$ and $\alpha_{2}$ :

$$
\begin{aligned}
\boldsymbol{\sigma}+\left(k \alpha_{1}\right) \mathbf{I} & \leq 0 \\
\boldsymbol{\sigma}-\alpha_{2} \mathbf{I} & \geq 0 \\
\alpha_{2} & \leq f_{t, \mathrm{eff}} \\
\alpha_{1}+\alpha_{2} & \leq f_{c, \mathrm{eff}} / k
\end{aligned}
$$

where $\mathbf{I}$ is the identity matrix of order 3 and $\sigma$ is the Cauchy stress tensor. The operators $\leq$ and $\geq$ are symbols for linear matrix inequalities, implying negative and positive semidefiniteness, respectively.

\section{Triaxial von Mises yield criterion for steel}

The von Mises yield criterion for a triaxial stress state can be written in the form:

$$
\begin{aligned}
& f\left(\sigma_{x x}, \sigma_{y y}, \sigma_{z z}, \sigma_{x y}, \sigma_{x z}, \sigma_{y z}\right)= \\
& \frac{1}{2}\left(\left(\sigma_{x x}-\sigma_{y y}\right)^{2}+\left(\sigma_{y y}-\sigma_{z z}\right)^{2}+\left(\sigma_{z z}-\sigma_{x x}\right)^{2}+6\left(\sigma_{x y}^{2}+\sigma_{x z}^{2}+\sigma_{y z}^{2}\right)\right)-f_{y}^{2}=0
\end{aligned}
$$


where $f_{y}$ is the material uniaxial yield stress. Considering the stress deviations between the normal stresses as single components, it can be seen that the yield criterion can be formulated as a second-order cone (Bisbos and Pardalos 2007):

$$
C\left(x_{1}, x_{2}, \ldots, x_{k}\right)=\sqrt{x_{2}^{2}+x_{3}^{2}+\cdots+x_{k}^{2}} \leq x_{1}
$$

The first six quadratic components need to be scaled to fit the formulation (12). Seven auxiliary variables accounting for this scaling are defined according to the number of unique stress components and the material yield strength:

$$
\begin{array}{ll}
\alpha_{1}=f_{y}, \quad \alpha_{2}=\frac{\sigma_{x x}-\sigma_{y y}}{\sqrt{2}}, & \alpha_{3}=\frac{\sigma_{y y}-\sigma_{z z}}{\sqrt{2}}, \quad \alpha_{4}=\frac{\sigma_{z z}-\sigma_{x x}}{\sqrt{2}} \\
\alpha_{5}=\sqrt{3} \sigma_{x y}, \quad \alpha_{6}=\sqrt{3} \sigma_{x z}, & \alpha_{7}=\sqrt{3} \sigma_{y z}
\end{array}
$$

The equations listed in (13) can be stated by the following constraints matrix:

$$
\left[\begin{array}{cccccc|ccccccc}
0 & 0 & 0 & 0 & 0 & 0 & 1 & 0 & 0 & 0 & 0 & 0 & 0 \\
-\frac{1}{\sqrt{2}} & \frac{1}{\sqrt{2}} & 0 & 0 & 0 & 0 & 0 & 1 & 0 & 0 & 0 & 0 & 0 \\
0 & -\frac{1}{\sqrt{2}} & \frac{1}{\sqrt{2}} & 0 & 0 & 0 & 0 & 0 & 1 & 0 & 0 & 0 & 0 \\
\frac{1}{\sqrt{2}} & 0 & -\frac{1}{\sqrt{2}} & 0 & 0 & 0 & 0 & 0 & 0 & 1 & 0 & 0 & 0 \\
0 & 0 & 0 & -\sqrt{3} & 0 & 0 & 0 & 0 & 0 & 0 & 1 & 0 & 0 \\
0 & 0 & 0 & 0 & -\sqrt{3} & 0 & 0 & 0 & 0 & 0 & 0 & 1 & 0 \\
0 & 0 & 0 & 0 & 0 & -\sqrt{3} & 0 & 0 & 0 & 0 & 0 & 0 & 1
\end{array}\right]\left[\begin{array}{c}
\sigma_{x x} \\
\sigma_{y y} \\
\sigma_{z z} \\
\sigma_{x y} \\
\sigma_{x z} \\
\sigma_{y z} \\
\alpha_{1} \\
\alpha_{2} \\
\alpha_{3} \\
\alpha_{4} \\
\alpha_{5} \\
\alpha_{6} \\
\alpha_{7}
\end{array}\right]=\left[\begin{array}{c}
f_{y} \\
0 \\
0 \\
0 \\
0 \\
0 \\
0
\end{array}\right]
$$

The von Mises yield criterion for a triaxial stress state can then be expressed in the form of the second-order cone (12):

$$
C_{\mathrm{vM}}(\boldsymbol{\alpha})=\alpha_{2}^{2}+\alpha_{3}^{2}+\alpha_{4}^{2}+\alpha_{5}^{2}+\alpha_{6}^{2}+\alpha_{7}^{2}-\alpha_{1}^{2}=0
$$

where $\boldsymbol{\alpha}^{\top}=\left[\alpha_{1}, \alpha_{2}, \alpha_{3}, \alpha_{4}, \alpha_{5}, \alpha_{6}, \alpha_{7}\right]$. It is required that a given stress state must be within or on the yield surface defined by the basis second-order cone i.e., $C_{\mathrm{vM}} \leq 0$.

Due to the relaxation of the stress equilibrium, as described previously, the element is able to establish spurious stress states for the von Mises yield criterion, i.e. equilibrium in the corner nodes is not violated, while elements contributing to the equilibrium have very large negative or positive hydrostatic stress states, respectively. This shortcoming is solved by imposing an additional linear inequality on each individual stress parameter governed by the von Mises yield criterion, in the form:

$$
-\chi f_{y} \leq \sigma \leq \chi f_{y}
$$

where $\chi$ is set to 1 in the most simple case. For the examples studied in this paper, this is a fair assumption. 


\section{Interface between material models}

No special considerations have been made in the modeling of the interface between rebars and the surrounding concrete. Therefore the model assumes a perfect bond at the interface. The perfect bond implies that the interface can only fail by a failure of either the Modified Mohr-Coulomb or von Mises yield criterion on either side of the interface, which in practice would mean failure in the concrete. This model would not be accurate for smooth rebars, which would have a low strength bond to the surrounding concrete and would experience a slip failure if not mechanically anchored. However, if ribbed rebars are considered, some mechanical bond will be present even for a straight bar, and it is reasonable to assume that a transfer of forces is possible between the rebar and the surrounding concrete, due to actions by the ribs.

\section{DETAILED OPTIMIZATION PROBLEM}

With the equilibrium matrix, $\boldsymbol{H}$, and the additional linear equations from the yield surfaces of the materials defined, the final assembly of the optimization problem can be made. In the implementation the optimization variables can be separated into three different categories: the element stress variables, $\sigma$, the load factor, $\lambda$, and the auxiliary variables, $\alpha$. The full system of linear equations is then given by:

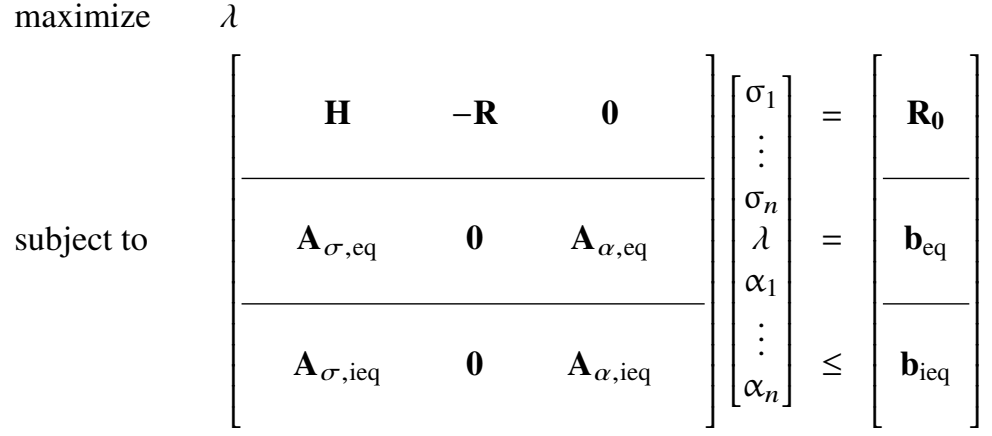

$$
\begin{aligned}
& f_{i}\left(\sigma_{i}, \alpha_{i}\right) \leq 0, \quad i=1, \ldots, n
\end{aligned}
$$

where the additional matrices $\mathbf{A}_{\sigma, \text { eq }}, \mathbf{A}_{\alpha, \text { eq }}, \mathbf{A}_{\sigma, \text { ieq }}, \mathbf{A}_{\alpha, \text { ieq }}$ and vectors $\mathbf{b}_{\text {eq }}, \mathbf{b}_{\text {ieq }}$ contain parameters defined from the implementation of the yield surfaces.

The stress variables in general have no upper or lower bounds, however, as will be described later, a lower and upper bound is implemented for the von Mises yield criterion to mitigate the formation of spurious stress states. The load factor, $\lambda$, has a lower bound of zero and no upper bound. The auxiliary variables are unbounded.

Besides the resulting load factor, $\lambda$, and stress variables, $\sigma$, the solution to the convex optimization problem also yields a set of parameters from the dual solution to the lower bound optimization problem, which can be interpreted as a plastic deformation mode. These parameters are linked to the equilibrium equations via $\mathbf{H}$, which ensure nodal equilibrium, and as such, provide a failure mechanism of the structure (Poulsen and Damkilde 2000).

\section{PROGRAMS AND COMPUTATIONAL REQUIREMENTS}

A program based on the theory described above has been implemented in Matlab (The Mathworks Inc. 2019) to generate the convex optimization problem, which is then 
solved using the commercial solver Mosek (MOSEK ApS 2019). The element meshes have been produced using GMSH (Geuzaine and Remacle 2009), and visualization has been performed using Paraview (Ayachit 2019).

Computations of the tension connection described later in this paper have required computers with memory in the range of $30 \mathrm{~GB}$ to $100 \mathrm{~GB}$ for the mesh discretization considered. These calculations have been performed on the High-Performance Computing (HPC) cluster at DTU.

\section{VALIDATION EXAMPLE: CONCRETE CYLINDER WITH SURROUNDING STEEL TUBE}

An example of a concrete cylinder in pure compression with a surrounding steel tube of thickness, $t$, is considered. The diameter of the cylinder is set to: $D=100 \mathrm{~mm}$, the height of the cylinder to: $h=2 D=200 \mathrm{~mm}$, and the thickness is varied between $t=$ $0 \mathrm{~mm}$ to $5 \mathrm{~mm}$ in steps of $1 \mathrm{~mm}$. A sketch of the example can be seen in Fig. 2. Typical concrete and steel parameters are used and can be seen in Table 1.

The analytical solution is found from a sliding failure of the Modified Mohr-Coulomb yield criterion. The steel tube will provide confining radial stresses, in the concrete core, equivalent to its yield capacity in uni-axial tension, $2 f_{y} t$. Thus, the principal stresses in a random material point inside the concrete core is given by: $\sigma=\left[f_{y} \frac{2 t}{D}, f_{y} \frac{2 t}{D}, p\right]$, which, when put into (7), yields the analytical solution for the compression capacity of the confined concrete: $p=f_{c}+4 f_{y} \frac{2 t}{D}$.

\section{Model and mesh}

The model is axisymmetric, and thus only a quarter of the cylinder was modeled. Besides the symmetry boundary conditions, a single point in the loading direction was also supported, to eliminate rigid body translation. The meshing was unstructured and controlled by a characteristic length, $l_{c}$, which is the target side length of the element

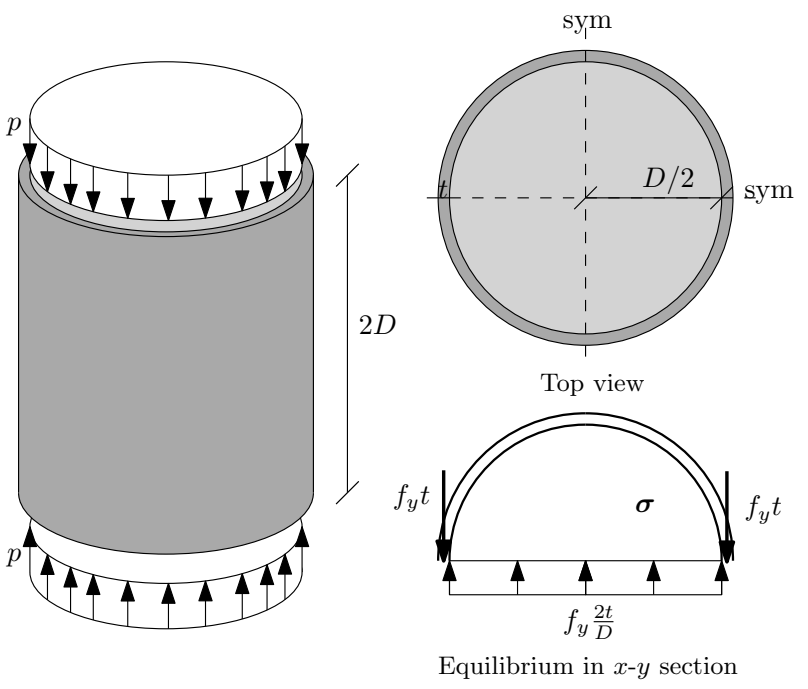

Fig. 2. Concrete cylinder in uniaxial compression with a steel tube providing confinement. 
the meshing algorithm aims at providing. An example mesh with $l_{c}=5 \mathrm{~mm}$ can be seen in Fig. 3.

\section{Results}

In Fig. 4, a graph showing the compressive stress capacity of the concrete cylinder as a function of the confinement stress is shown. The graph shows that even for the roughest mesh with a characteristic length of $l_{c}=10 \mathrm{~mm}$, an accurate solution is obtained. This result validates that the framework can find the optimal solution for a structure consisting of both steel and concrete, modeled separately.

\section{APPLICATION EXAMPLE: TENSION CONNECTION USING OVERLAPPING U-BARS}

To show the ability of the presented framework for a practical example, a tension connection using overlapping U-bars is considered. The connection has been the topic of a experimental study by Jørgensen and Hoang (2013), and the numerical results will be compared to results from the experimental work. A schematic of the experimental setup can be seen in Fig. 5, with model parameters shown in Table 2. The experiment consists of 30 pairwise identical specimens with varying amount of transverse reinforcement, spacing between overlapping U-bars, length of overlap, and diameter of overlapping U-bars.

\section{Model}

The experimental setup is symmetric about two axes transverse to the loading direction, this is utilized to only model a quarter of the test setup using symmetry boundary conditions. Furthermore, since the test setup is designed to fail in the joint concrete, only the joint region itself is modeled.

Table 1. Material properties used in the compression test.

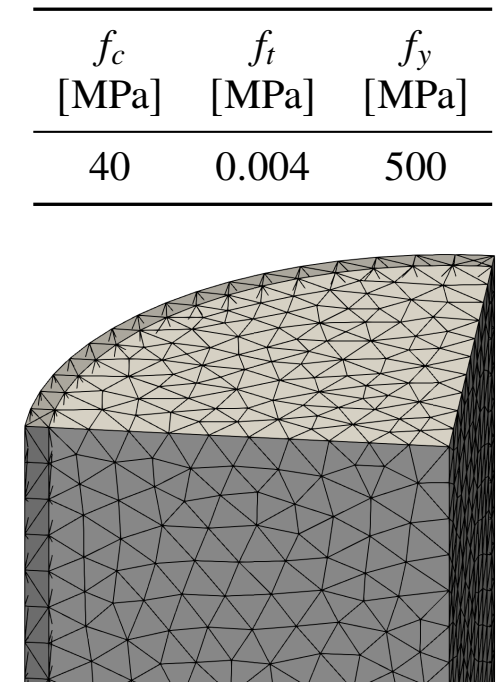

Fig. 3. Part of mesh for $t=2 \mathrm{~mm}$ and $l_{c}=5 \mathrm{~mm}$. 
The walls of the joint surface were greased before casting of the joint. For this reason, it was assumed that no friction or cohesion was present on these surfaces. The paper by Jørgensen and Hoang reports that, typically, the first cracks that appeared were splitting cracks along the two joint surfaces, and that they appeared at relative joint deformations in the order of $5 \%$ to $12.5 \%$ of the ultimate deformation capacity. This seems to indicate a significant separation of the joint surfaces at the ultimate limit state. Because of this, the joint concrete surfaces were assumed to be free.

The two diaphragms on either side of the joint were assumed to be strong and stiff enough to prevent transverse displacement of the longitudinal U-bars. For this reason, the surfaces of the longitudinal rebars were fixed at the joint surfaces.

A figure of the model with loads and supports can be seen in Fig. 6. An arrow in each corner of the surface indicates that the surface was supported in that direction. The load, $p$, was applied as a surface unit load. The total capacity of the test specimen was then given by $N_{n u m}=4 A_{p} p \lambda$, where $A_{p}$ is the cross-sectional area of the rebar on which the load was applied and $\lambda$ is the load factor.

\section{Mesh}

The mesh discretization was controlled by a characteristic length denoted $l_{c}$. The geometry of the curved U-bars is essential for the correct transfer of stresses to the concrete. For this reason, the mesh was made finer in these regions. The refinement was achieved by prescribing a minimum number of points required when discretizing a circle. The minimum number of points on the circle denoted $n_{\text {circ }}$ was determined as a function of the characteristic length, $l_{c}$, and the transverse rebar diameter, $\phi_{T}$, by: $n_{\text {circ }}=4 \frac{\phi_{T} \pi}{l_{c}}$. The results were rounded up to the nearest integer. The factor 4 is simply a scaling factor. For low values of $l_{c}$, the meshing of especially the transverse rebars was still quite rough. GMSH meshes curved surfaces by distributing points on the surface and generating elements from these. This method produces a cross-sectional area of the rebars that is too small. This is illustrated in the 2D case in Fig. 7. The problem was mitigated by iteratively changing the rebar diameter until the cross-sectional area was

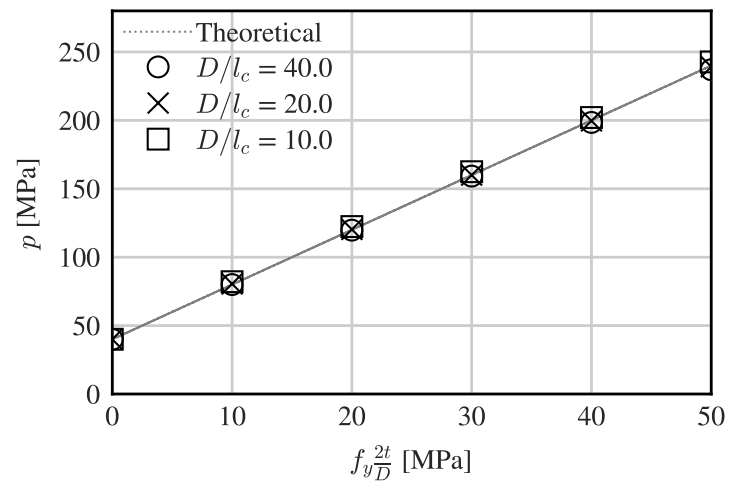

Fig. 4. Cylinder capacity as a function of confinement for three different characteristic lengths $l_{c}$. 


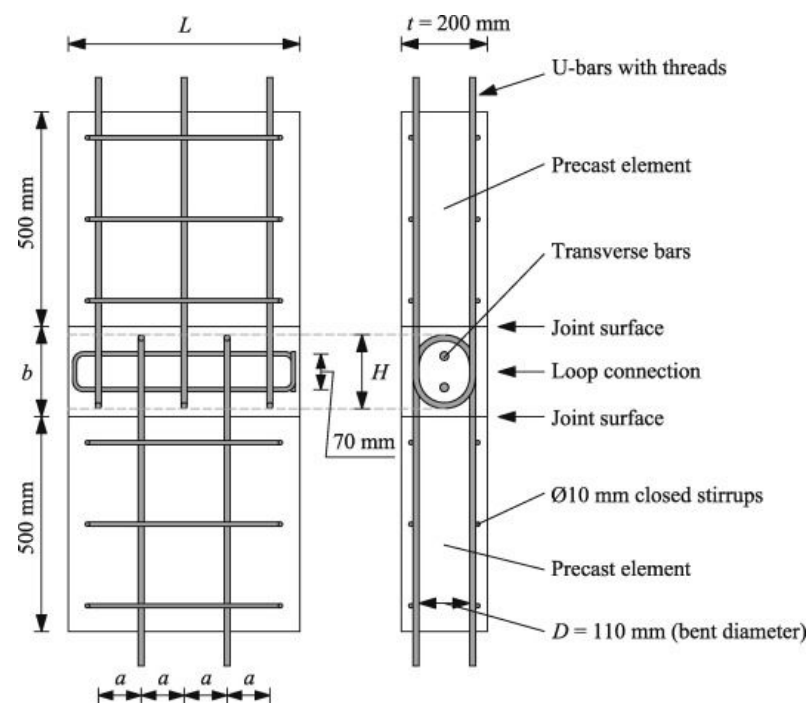

Fig. 5. Schematic of the experiment carried out at The University of Southern Denmark. (Reprinted from Engineering Structures, Vol. 52, H. B. Joergensen and L. C. Hoang, "Tests and limit analysis of loop connections between precast concrete elements loaded in tension," pp. 558-569, (c) 2013, with permission from Elsevier.)

Table 2. Geometry, properties and results of tested connections.

\begin{tabular}{|c|c|c|c|c|c|c|c|c|c|c|c|}
\hline $\begin{array}{l}\text { Series } \\
\text { ID }\end{array}$ & $\begin{array}{l}\text { Specimen } \\
\text { ID }\end{array}$ & $\begin{array}{c}b \\
{[\mathrm{~mm}]}\end{array}$ & $\begin{array}{c}L \\
{[\mathrm{~mm}]}\end{array}$ & $\begin{array}{c}a \\
{[\mathrm{~mm}]}\end{array}$ & $\begin{array}{c}H \\
{[\mathrm{~mm}]}\end{array}$ & $\begin{array}{c}\phi_{T} \\
{[\mathrm{~mm}]}\end{array}$ & $\begin{array}{c}\phi_{L} \\
{[\mathrm{~mm}]}\end{array}$ & $\begin{array}{c}f_{c} \\
{[\mathrm{MPa}]}\end{array}$ & $\begin{array}{c}f_{y T} \\
{[\mathrm{MPa}]}\end{array}$ & $\begin{array}{c}f_{y L} \\
{[\mathrm{MPa}]}\end{array}$ & $\begin{array}{c}N_{U, t e s t} \mathrm{~A} \text { and } \mathrm{B} \\
{[\mathrm{kN}]}\end{array}$ \\
\hline \multirow{3}{*}{ Series 1} & $1 \mathrm{~A}$ and $1 \mathrm{~B}$ & 210 & 540 & 100 & 170 & 6 & 12 & 38.4 & 650.4 & 583.3 & 214.6 and 191.1 \\
\hline & $2 \mathrm{~A}$ and $2 \mathrm{~B}$ & 210 & 540 & 100 & 170 & 6 & 16 & 38.4 & 650.4 & 591.3 & 206.8 and 218.7 \\
\hline & $3 \mathrm{~A}$ and $3 \mathrm{~B}$ & 210 & 540 & 100 & 170 & 6 & 20 & 38.4 & 650.4 & 560.9 & 206.9 and 205.3 \\
\hline \multirow{3}{*}{ Series 2} & $4 \mathrm{~A}$ and $4 \mathrm{~B}$ & 210 & 540 & 100 & 170 & 8 & 12 & 38.4 & 553.4 & 583.3 & 243.8 and 230.1 \\
\hline & $5 \mathrm{~A}$ and $5 \mathrm{~B}$ & 210 & 540 & 100 & 170 & 8 & 16 & 38.4 & 553.4 & 591.3 & 252.9 and 221.8 \\
\hline & $6 \mathrm{~A}$ and $6 \mathrm{~B}$ & 210 & 540 & 100 & 170 & 8 & 20 & 38.4 & 553.4 & 560.9 & 238.8 and 269.8 \\
\hline \multirow{3}{*}{ Series 3} & $7 \mathrm{~A}$ and $7 \mathrm{~B}$ & 210 & 540 & 100 & 170 & 10 & 12 & 38.4 & 632.1 & 583.3 & 273.1 and 248.5 \\
\hline & $8 \mathrm{~A}$ and $8 \mathrm{~B}$ & 210 & 540 & 100 & 170 & 10 & 16 & 38.4 & 632.1 & 591.3 & 281.0 and 297.6 \\
\hline & $9 \mathrm{~A}$ and $9 \mathrm{~B}$ & 210 & 540 & 100 & 170 & 10 & 20 & 38.4 & 632.1 & 560.9 & 281.4 and 285.3 \\
\hline \multirow{3}{*}{ Series 4} & $10 \mathrm{~A}$ and $10 \mathrm{~B}$ & 210 & 460 & 80 & 170 & 10 & 20 & 38.4 & 632.1 & 560.9 & 387.1 and 391.4 \\
\hline & $11 \mathrm{~A}$ and $11 \mathrm{~B}$ & 210 & 380 & 60 & 170 & 10 & 20 & 38.4 & 632.1 & 560.9 & 459.6 and 419.6 \\
\hline & $12 \mathrm{~A}$ and $12 \mathrm{~B}$ & 210 & 300 & 40 & 170 & 10 & 20 & 38.4 & 632.1 & 560.9 & 509.4 and 595.3 \\
\hline \multirow{3}{*}{ Series 5} & $13 \mathrm{~A}$ and $13 \mathrm{~B}$ & 265 & 540 & 100 & 225 & 10 & 20 & 38.4 & 632.1 & 560.9 & 479.5 and 470.5 \\
\hline & $14 \mathrm{~A}$ and $14 \mathrm{~B}$ & 340 & 540 & 100 & 300 & 10 & 20 & 38.4 & 632.1 & 560.9 & 571.6 and 550.7 \\
\hline & $15 \mathrm{~A}$ and $15 \mathrm{~B}$ & 490 & 540 & 100 & 450 & 10 & 20 & 38.4 & 632.1 & 560.9 & 597.5 and 648.4 \\
\hline
\end{tabular}

Source: Reprinted from Engineering Structures, Vol. 52, H. B. Joergensen and L. C. Hoang, "Tests and limit analysis of loop connections between precast concrete elements loaded in tension," pp. 558-569, (C) 2013, with permission from Elsevier. 
correct within a tolerance of $1 \mathrm{~mm}^{2}$.

Specimen 5 was chosen as a representative specimen for a convergence analysis, to determine the validity of the solutions, and to determine the required mesh discretization. The specimen model was subjected to a convergence analysis with the characteristic length, $l_{c}$, ranging from $20 \mathrm{~mm}$ to $5.25 \mathrm{~mm}$, with a $25 \%$ decrease for each calculation. No effectiveness factor on the concrete compressive strength was considered, and for the tensile strength, a value of $f_{t \text {,eff }}=f_{c \text {,eff }} / 10000$ was used. This value was sufficiently small to improve numerical stability while not influencing the results. The convergence plot can be seen in Fig. 8 and in tabulated form in Table 3. The solution for $l_{c}=8.2 \mathrm{~mm}$ was considered to be sufficiently accurate. Therefore $l_{c}$ was chosen as $l_{c}=8.0 \mathrm{~mm}$ for further calculations. Figure 9 shows an example of the surfaces of a mesh with this discretization.

\section{Calibration of the effectiveness factor}

When using rigid-plastic modeling of concrete structures, the strength needs to be reduced by an effectiveness factor, since concrete does not behave like a perfectly rigidplastic material. Jørgensen and Hoang (2013) proposed an effectiveness factor for the connection based on beam shear problems:

$$
v=\frac{0.88}{\sqrt{f_{c}}}\left(1+\frac{1}{\sqrt{H}}\right)
$$

where $H$ is the height of the joint region. Equation (18) gives values for the effectiveness factor between 0.35 and 0.49 . The effectiveness factor is model specific and should be calibrated from experimental results. For problems where shear is critical for the capacity, a low effectiveness factor is expected.

Calculations are run for all 15 specimens, with characteristic length $l_{c}=8.0 \mathrm{~mm}$ and effectiveness factor $v=0.20,0.25,0.30,0.35,0.40$ and 0.50 . Comparison between

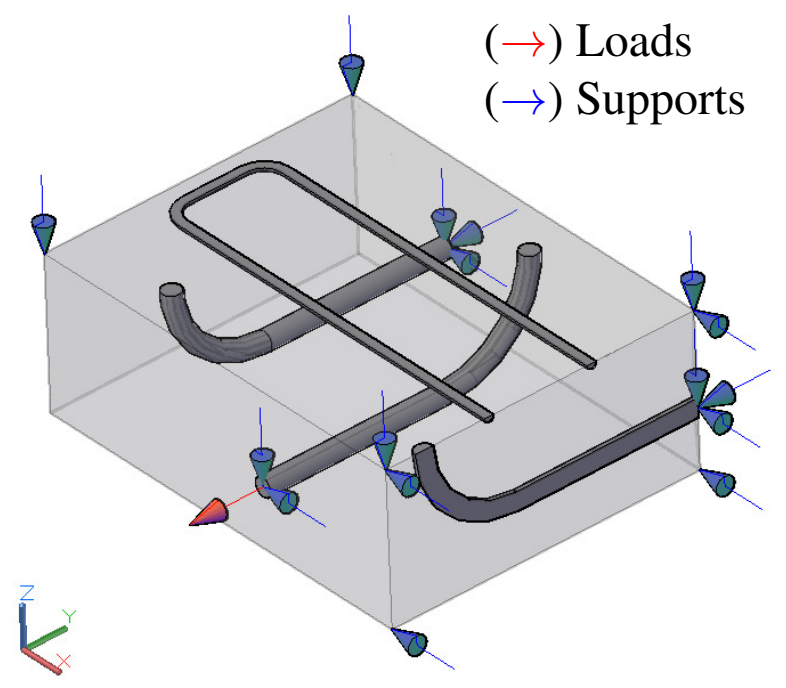

Fig. 6. Supports and loads of the model. A blue arrow in either side of a surface means the entire surface is supported. 

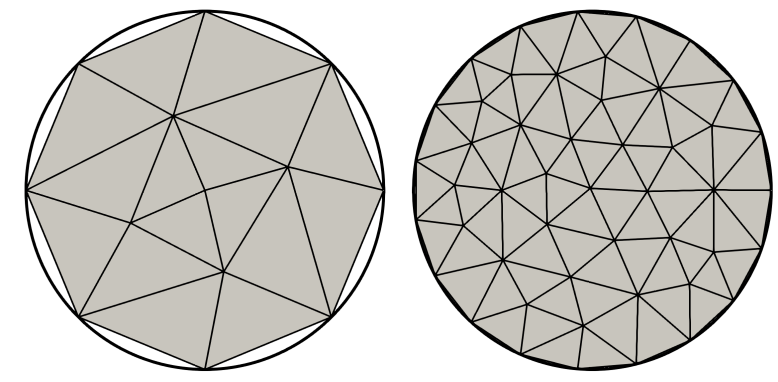

Fig. 7. Low and high resolution meshing of a circle.

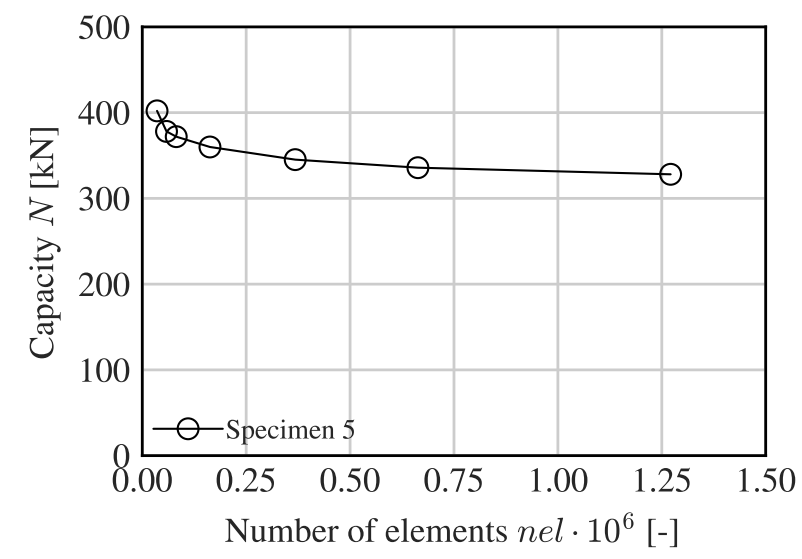

Fig. 8. Results of convergence analysis for specimen 5.

Table 3. Convergence of solution for different mesh dizcretization for specimen 5.

\begin{tabular}{rrr}
\hline $\begin{array}{c}l_{c} \\
{[\mathrm{~mm}]}\end{array}$ & \multicolumn{1}{c}{$\begin{array}{c}\text { nel } \\
{[-]}\end{array}$} & $\begin{array}{l}N_{\text {num }} \\
{[\mathrm{kN}]}\end{array}$ \\
\hline 20.00 & 35533 & 402.1 \\
16.00 & 58348 & 378.1 \\
12.80 & 81723 & 372.0 \\
10.24 & 162858 & 359.9 \\
8.19 & 367982 & 345.2 \\
6.55 & 663226 & 335.8 \\
5.24 & 1271293 & 328.1 \\
\hline
\end{tabular}


the experimental results, $N_{\text {test }}$, and numerical results, $N_{\text {num }}$, can be seen in Fig. 10, together with the basic statistics of $N_{\text {num }} / N_{\text {test }}$. The values for $N_{\text {test }}$ is the average value of the two experiments performed for each specimen. The effectiveness factor that gives results closest to the experimental data is 0.25 , which has the mean value closest to unity and results that are generally distributed quite close to the theoretical line.

This effectiveness factor is quite low even for shear problems, but as previously mentioned, the effectiveness factor is model specific, and a FELA-calculation can utilize the material in a much more optimized manner than hand calculations. Because of this, it is reasonable that a lower effectiveness factor should be considered when using FELA. For the rest of the results in this section, an effectiveness factor of $v=0.25$ has been applied. This is the effectiveness factor used in all elements of the model, while in practice only the critical areas of the model would have an effectiveness factor this low. In reality, different effectiveness factors should be employed in different regions of the model, corresponding to the stress state experienced by the concrete in these regions. This limitation has previously been tackled for plane problems by incorporation the effectiveness factor into the yield surface (Herfelt et al. 2018), which has not been done for triaxial stress states.

\section{Stress distributions and failure mechanisms}

Specimen 5 is again chosen as a representative specimen, and will in the following be studied in detail. First, the stress state will be studied by analyzing principal stress vector plots together with principal equivalent strain vector plots. Since a rigid-plastic material model is used the magnitude of the strains are unknown. Therefore, the equivalent strains are derived from the failure mechanism and are indicators of yielding. Lastly, the failure mechanism will be studied and compared for the different specimens.

Figure 11 shows a plot of the smallest and largest principal stress vectors, $\sigma_{1}$ and $\sigma_{3}$, and the smallest and largest principal equivalent strain vectors, $\varepsilon_{1}$ and $\varepsilon_{3}$. The concrete struts going from adjacent U-bars is seen when looking at the plot of $\sigma_{3}$. The struts originate from the relatively little surface area of the bend of the U-bars and bulge out at the center of the strut. This bulging is possible due to the confinement provided by
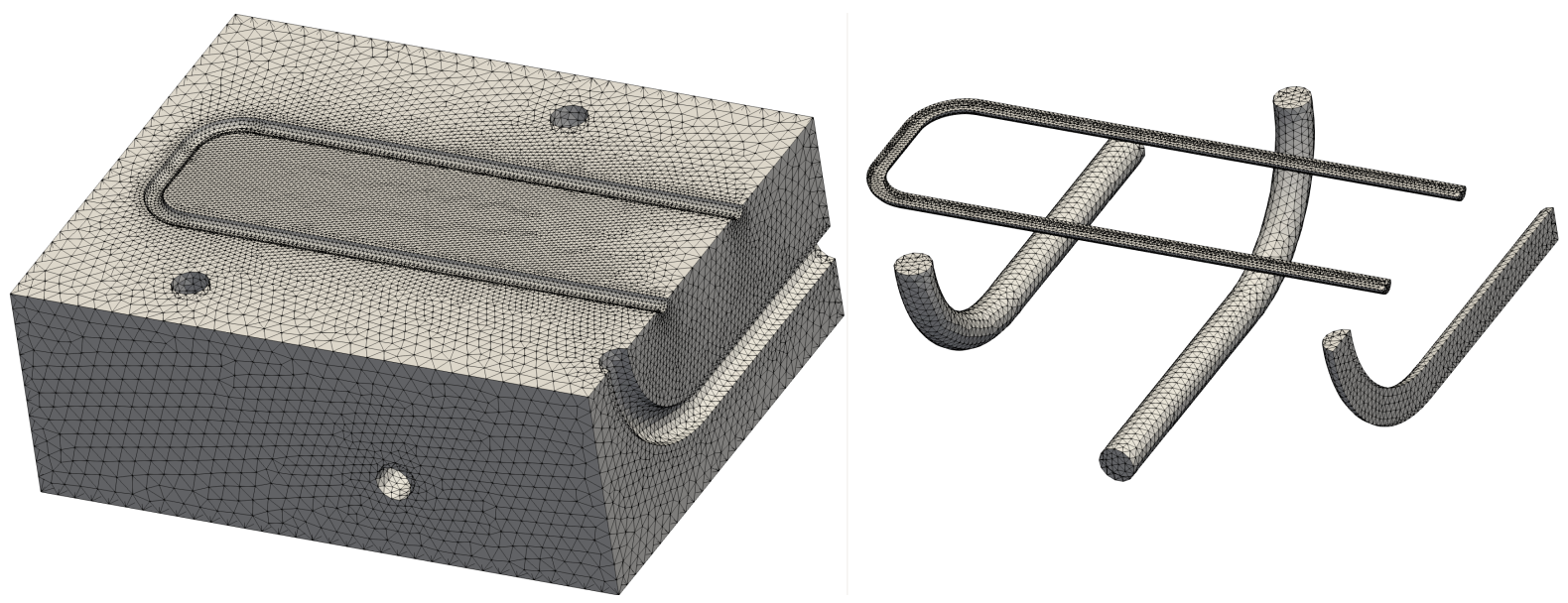

Fig. 9. Mesh of specimen 5 with $l_{c}=8.0 \mathrm{~mm}$. 
the transverse reinforcement since the concrete itself is modeled with negligible tensile strength. At the bends of the U-bars and at the bends of the transverse reinforcement, large triaxial stresses are present, due to a local state of confinement. Tensile stresses are carried in the reinforcement, and as can be seen on the $\sigma_{1}$ plot, all of the available reinforcement is utilized.

The smallest principal strain, $\varepsilon_{3}$, can be used as an indicator of where crushing takes place in the concrete, i.e., where the concrete is contracting in the failure mechanism. This contraction is present in a band going from the loaded U-bar towards the U-bar at the symmetry boundary condition, almost no crushing takes place between the loaded U-bar and the outer U-bar. The last plot shows the largest principal strain, $\varepsilon_{1}$, which is an indicator of were separation is occurring. Separation takes place perpendicular to the crushing zone, as well as in two distinct zones on the left side of the loaded U-bar. The separation, which is present perpendicular to the concrete struts, arises from the tensile stresses, which are a product of the bulging strut. The fact that relatively large strains are present here is a good indicator of why such a low effectiveness factor is found since several authors have shown that transverse tensile strain lowers concrete compressive strength (Hoang et al. 2012). Some separation also takes place in the region just left of the loaded U-bar; an explanation for this requires study of the failure mechanism.

The failure mechanism reported by Jørgensen and Hoang consisted of splitting cracks at the joint surfaces, and lines of fractures going from the bends on either side of adjacent U-bars. This failure mechanism was reported to mainly consist of the pullout of the two central U-bars with their associated concrete core. The pullout was accompanied with a lateral motion of the outside section. The simplified mechanism they assumed in their upper bound solution can be seen in Fig. 12. The figure includes numbering of the different parts of the failure mechanism, which the following text will refer to.

The deformations in the FELA calculations were similar to the upper bound solution for specimens 1 to 8 and 10 to 14. A representative example can be seen in Fig. 13. Figure 13a shows the deformed shape of the specimen with strain vectors for the smallest and largest principal strains. A large part of the mechanism is similar to the simplified mechanism from Fig. 12. Part (1) and (3) behaves almost exactly as stated. However, a large difference is apparent with part (2). Instead of moving laterally, it rotates around the supported part of the outside U-bar. The mechanism is further visualized in Fig. 13b, which shows the relative movement of the collapse as a vector field. The fact that part (2) rotates, instead of rigid body translation as the hand calculation prescribed, explains the difference in strain distribution on either side of the loaded U-bar. From Fig. 13a, it can be seen that the outer rebar bends around a plastic hinge at the supporting surface of the outer rebar. From this figure, it can also be seen that some degree of yielding is also present in the loaded U-bar with one plastic hinge, and in the transverse U-bar with several plastic hinges.

Some difference is present in the failure mechanism of specimen 9 and 15 . Specimen 9 experience yielding of the U-bar at the symmetry boundary condition, meaning that part (1) and (3) move together. The mechanism is visualized in Fig. 14. Part (1) and (3) move almost entirely in the longitudinal-direction, some bending of the outside U-bar is still present, but here the transverse rebar is stiff enough so that only a piece of part 
(2) moves. This movement is analog to spalling of the corner concrete pushed aside by the bending U-bar.

The primary failure of specimen 15 can best be described as spalling of the concrete on the outside of the joint. In fact, for specimen 13-15, a gradual change in the previously described mechanism takes place. This can be seen in Fig. 15. The confinement stemming from the transverse rebar was not able to spread throughout the specimen when $H$ was increased, while the transverse rebars remained at the center of the joint. Therefore the primary failure became spalling.

The failure mechanism of the FELA calculations was generally in line with what was reported by Jørgensen and Hoang from the experimental work. Pictures of the specimens after removal of the cover showed cracks coresponding to the areas of large equivalent principal strains in Fig. 13. Furthermore, the experimental results from specimens 9 and 15 also showed different failures with yielding and spalling, respectively.

\section{Comparison of capacities}

Figure 16 shows the dependency on the ratio $a / H$ on the capacity of the connection, the ratio is changed while keeping either $a$ or $H$ constant, yielding two different situations. It is seen that a lower $a / H$ ratio, that is either: larger overlap of the U-bars, $H$; or smaller distance between U-bars, $a$; yields higher capacity. This result is in line with the conclusions by Jørgensen and Hoang, and the numerical results generally show good agreement with the experimental results. Interestingly the FELA calculations give the same capacity in the two situations, which was not the conclusion from the experiments. However, since the FELA calculation assumes a negligible tensile capacity of the concrete, and therefore has no way of transferring shear between the rebars and concrete except for the shear enabled by confinement, the effect of a larger overlap is not felt. For this model, with all other parameters remaining constant, the slope of the compressive struts, originating at the bend of either U-bar, is the parameter of importance.

Likewise, Jørgensen and Hoang also concluded that a larger ratio of transverse reinforcement (here indicated by the diameter of the transverse U-bars, $\phi_{T}$ ) results in a larger capacity. This observation is also the case for the numerical results, see Fig. 17. Nevertheless, it seems like the FELA model overestimates this effect based on the limited data available.

From Fig. 18, it can be concluded that an increase in the diameter of the longitudinal U-bars increases the capacity of the connection. This conclusion differs from the conclusion by Jørgensen and Hoang based on the experimental data. The experimental data even suggests a slight decrease in capacity from $\phi_{L}=16 \mathrm{~mm}$ to $\phi_{L}=20 \mathrm{~mm}$. However, this could be due to the inherent variability of experimental work, rather than an effect of the U-bar diameter itself. Dependence of the longitudinal rebars is expected when comparing the resulting capacities to the failure mechanism reported in the previous section. The capacity of the concrete strut, going from the loaded U-bar towards the outer U-bar, is limited by the lateral capacity of the system. In this case, the confinement provided by the transverse U-bars and the bending capacity of the U-bar itself. The dependency of $N_{\text {num }}$ on $\phi_{L}$ appears to be linear. 

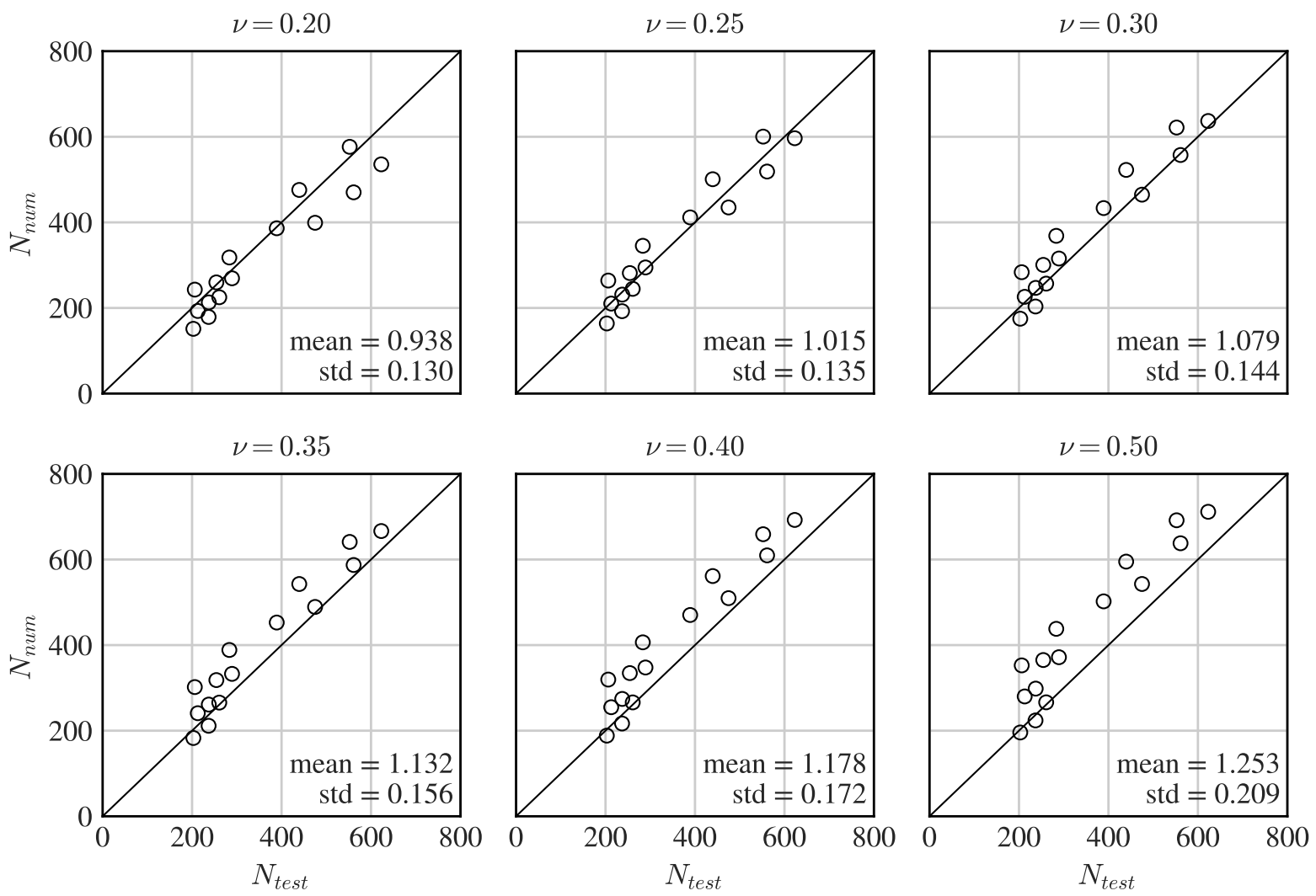

Fig. 10. Comparison between experimental results, $N_{\text {test }}$, and numerical results, $N_{\text {num }}$, for different values of the concrete effectiveness factor. In the plots the lines corresponding to $N_{\text {num }}=N_{\text {test }}$ are shown together with basic statistics for $N_{\text {num }} / N_{\text {test }}$. 


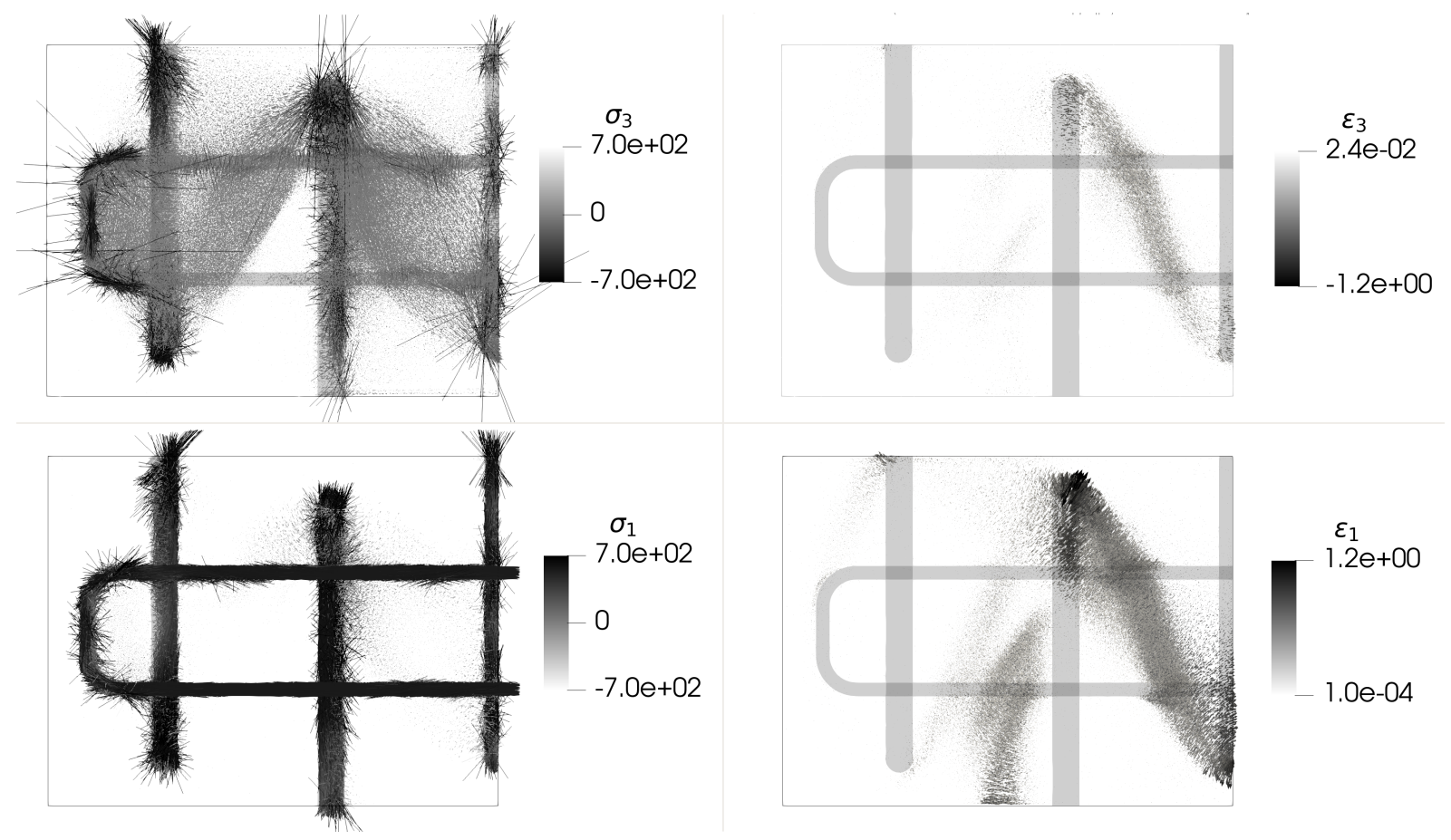

Fig. 11. principal stress vectors and principal equivalent strain vectors for specimen 5 .

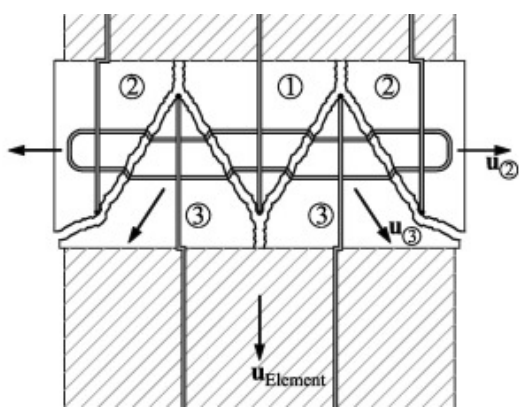

Fig. 12. Rigid body motion assumed by Jørgensen and Hoang in their upper bound solution. Note that the mechanism in this sketch show the entire specimen. (Reprinted from Engineering Structures, Vol. 52, H. B. Joergensen and L. C. Hoang, "Tests and limit analysis of loop connections between precast concrete elements loaded in tension," pp. 558-569, @ 2013, with permission from Elsevier.) 


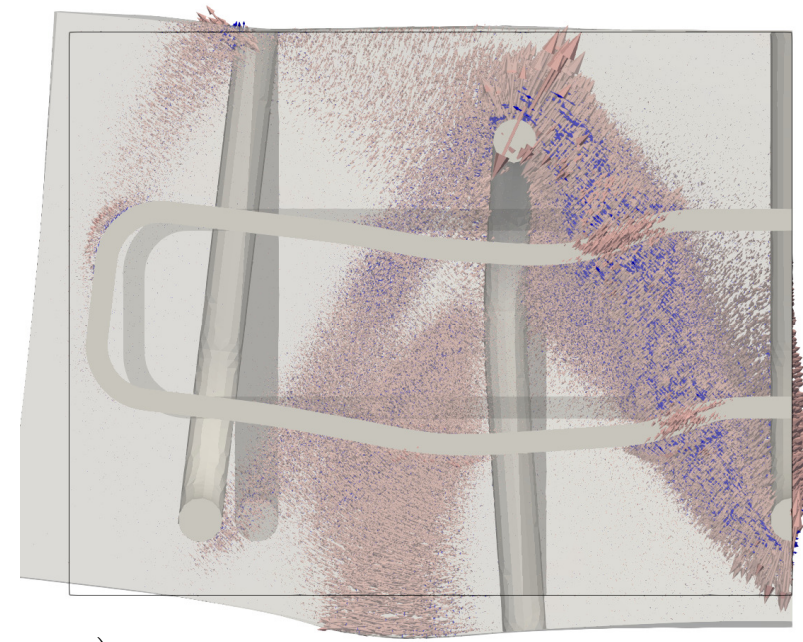

a)

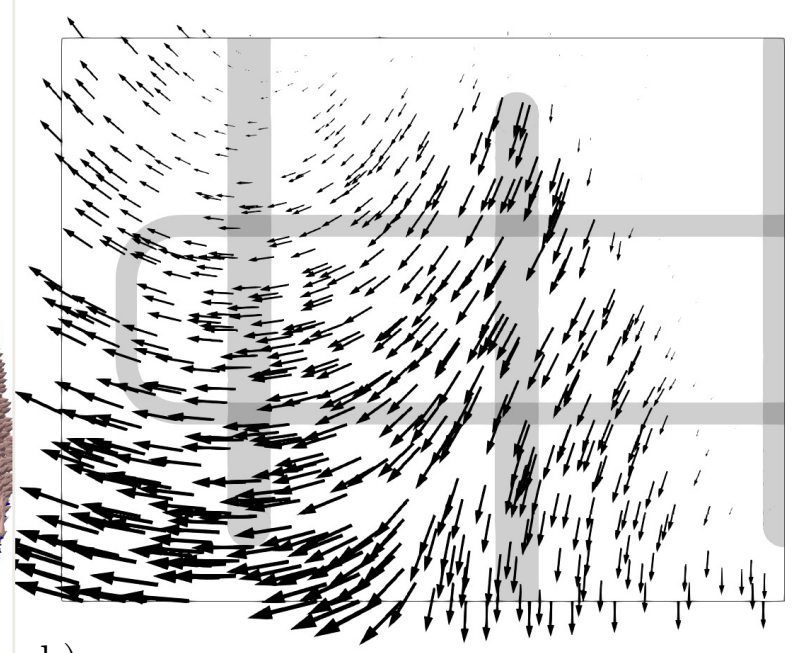

b)

Fig. 13. Failure mechanism of specimen 5 shown as: a) deformed shape with smallest (blue) and largest (red) principal strain vectors, and b) undeformed shape with deformation vectors.

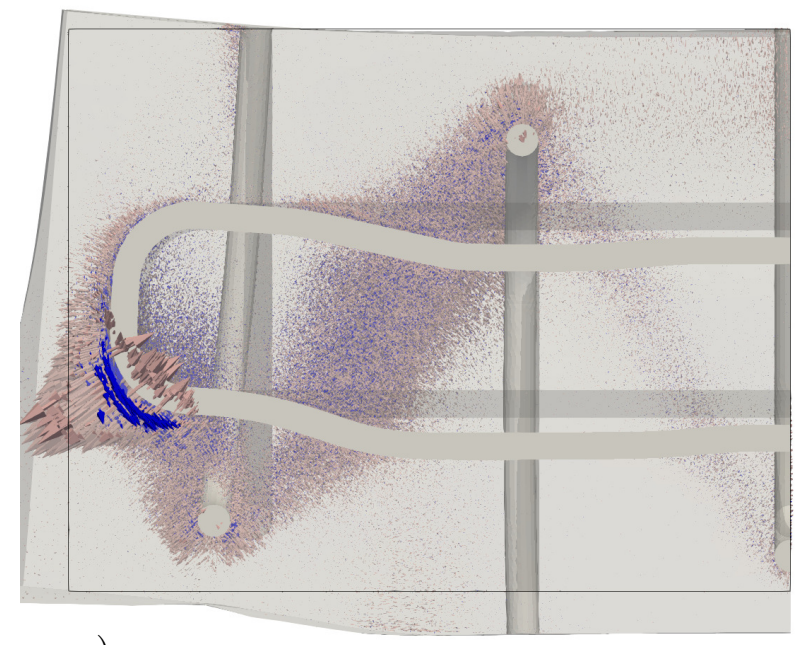

a)

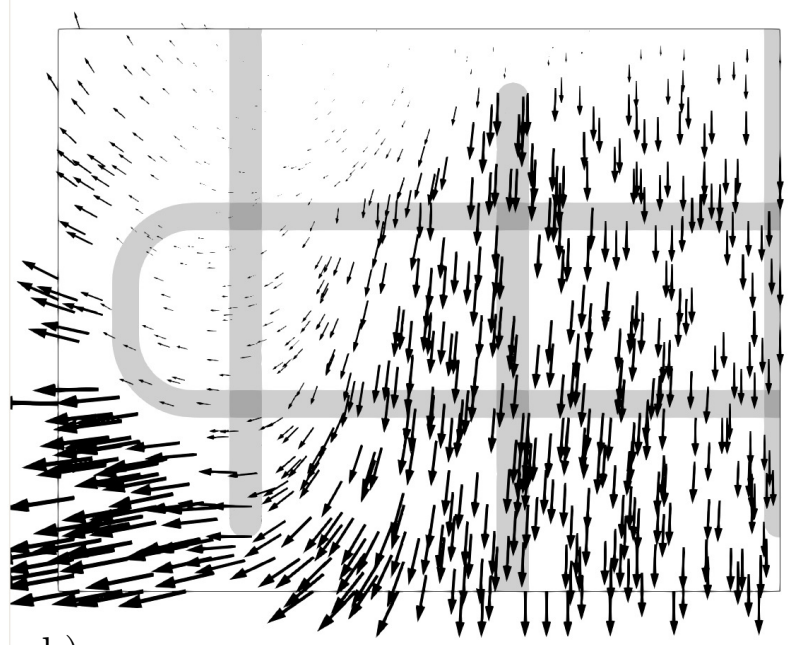

b)

Fig. 14. Failure mechanism of specimen 9 shown as: a) deformed shape with smallest (blue) and largest (red) principal strain vectors, and b) undeformed shape with deformation vectors. 

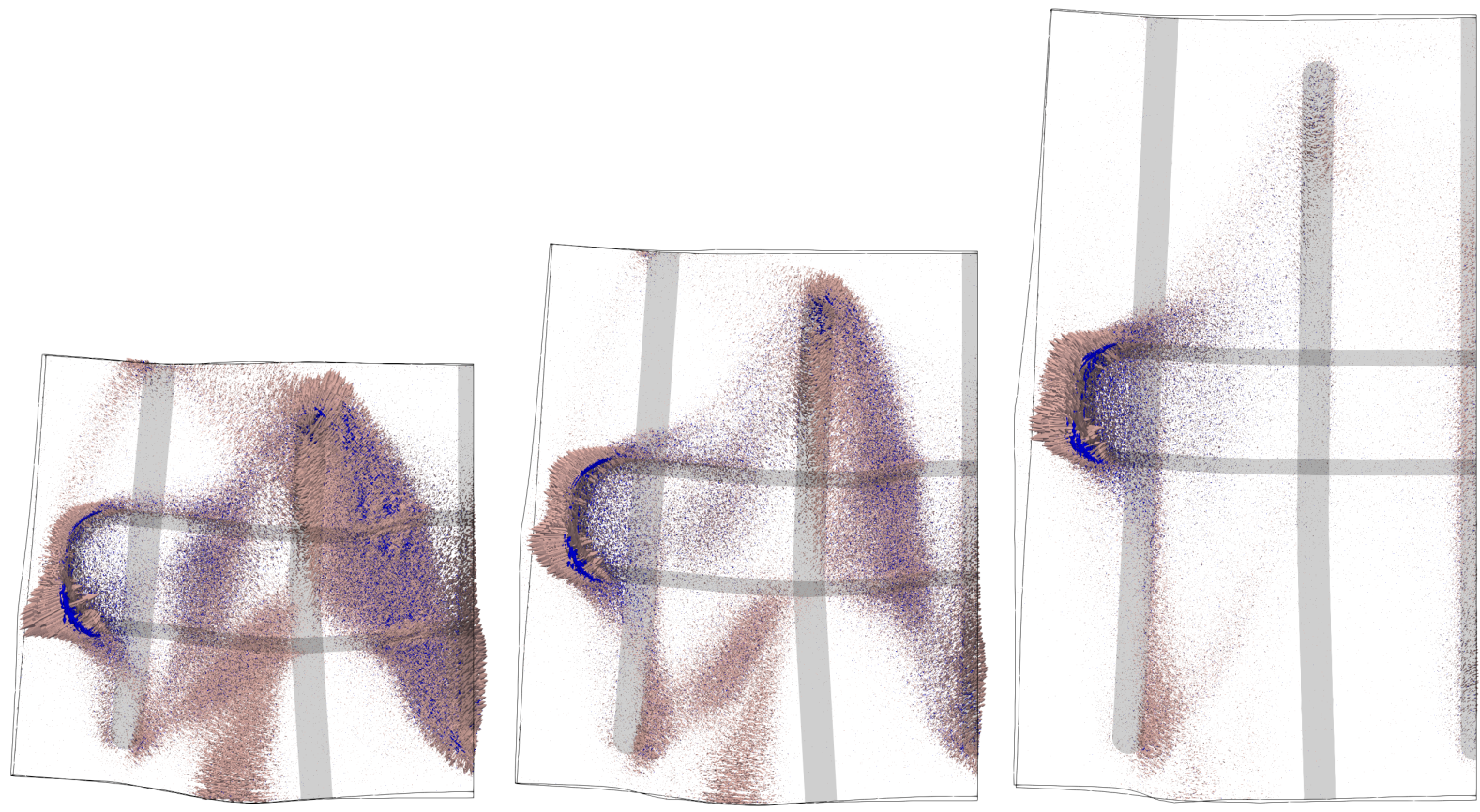

Fig. 15. Failure mechanism of specimen 13 to 15 with smallest (blue) and largest (red) principal strain vectors.

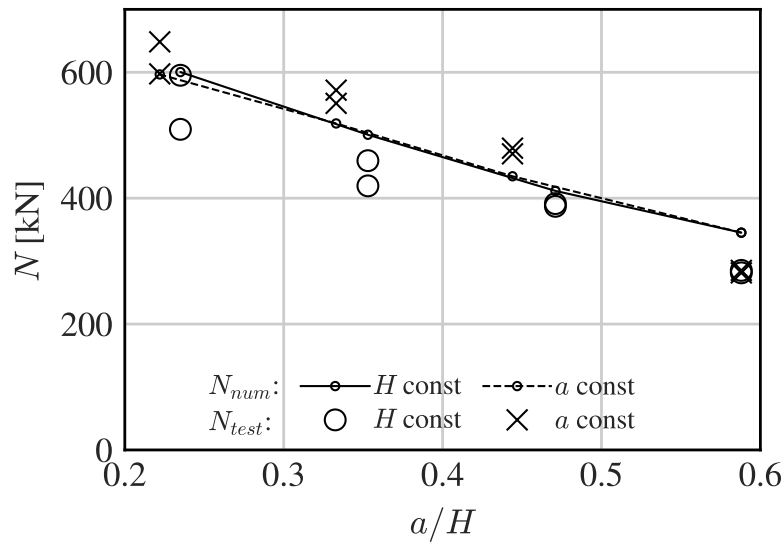

Fig. 16. Comparison of results as a function of the ratio $a / H$ with either U-bar spacing, $a$, or U-bar overlap, $H$, varying. 


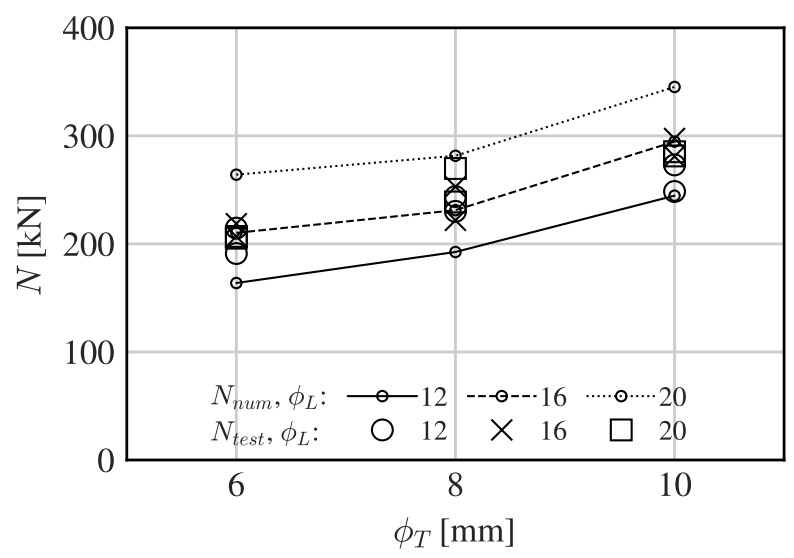

Fig. 17. Comparison of results as a function of transverse reinforcement amount, $\phi_{T}$, for varying longditudinal rebar diameters, $\phi_{L}$.

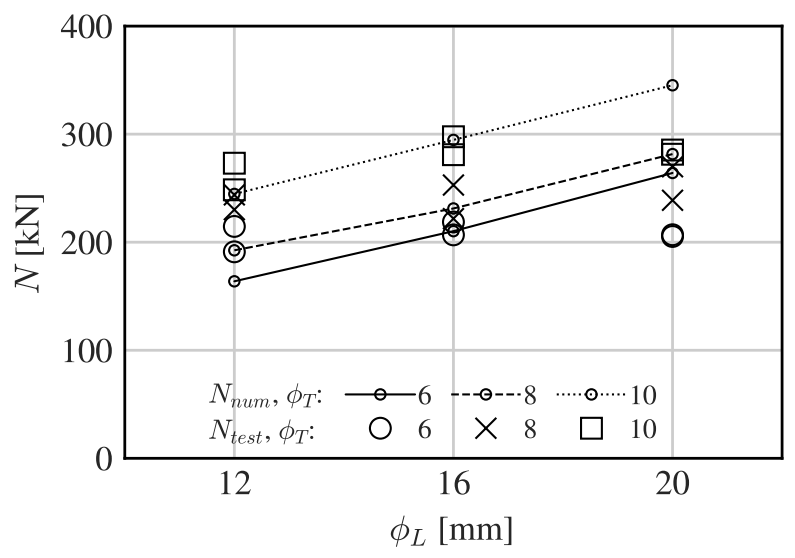

Fig. 18. Comparison of results as a function of the longditudinal rebar diameter, $\phi_{L}$, for varying transverse reinforcement amount, $\phi_{T}$. 


\section{CONCLUSION}

A framework for the analysis of three dimensional reinforced concrete structures with triaxial stress states has been implemented. The framework is based on Finite Element Limit Analysis (FELA), and both the Modified Mohr-Coulomb and von Mises yield criteria have been implemented for modeling of concrete and steel, respectively. The FELA framework uses a computationally inexpensive tetrahedral element, which has made it possible to model complex geometries using more than a million elements.

Specimens from experimental work on tensile loop connections were modeled. A comparison of model results versus numerical results was used to calibrate the concrete effectiveness factor, $v$, and the best fit was found with $v=0.25$. This result was surprisingly low, even for a problem where shear is critical. However, it must be expected to find lower effectiveness factors for FELA than hand calculations, since results from FELA calculations are greatly optimized and uses the material very efficiently.

The failure mechanism and stress distribution for a U-bar tension connection with varying geometry and rebar sizes were analyzed. The failure mechanism and stress distribution were concluded to be meaningful and in line with crack patterns reported for the experiments. The capacity of the loop connection from the numerical calculation was compared to the experimental capacity. The capacity was studied as a function of different parameters, and good correspondence with test results was found.

\section{DATA AVAILABILITY STATEMENT}

Some or all data, models, or code that support the findings of this study are available from the corresponding author upon reasonable request.

\section{ACKNOWLEDGMENT}

The work presented in this paper has been financially supported by the Innovation Fund Denmark (grant no. 9065-00056B) and the COWI Foundation (grant no. T143.08). The first author would like to thank and recognize the work done by Nikolaj Skafte Koch in their joint master thesis, which has served as a basis for this paper.

\section{REFERENCES}

Anderheggen, E. and Knöpfel, H. (1972). "Finite element limit analysis using linear programming." International Journal of Solids and Structures, 8(12), 1413-1431.

Andersen, M. E. M. and Koch, N. S. (2018). "Three Dimensional Finite Element Limit Analysis of Reinforced Concrete Structures." Master's thesis, Technical University of Denmark (DTU), Kgs. Lyngby, <https://findit.dtu.dk/en/catalog/2437945966>.

Ayachit, U. (2019). The ParaView Guide. Kitware Inc., <http://paraview.org > .

Bisbos, C. D., Makrodimopoulos, A., and Pardalos, P. M. (2005). "Second-order cone programming approaches to static shakedown analysis in steel plasticity." Optimization Methods and Software, 20(1), 25-52.

Bisbos, C. D. and Pardalos, P. M. (2007). "Second-Order Cone and Semidefinite Representations of Material Failure Criteria." Journal of Optimization Theory and Applications, 134(2), 275-301.

Borges, L. A., Zouain, N., and Huespe, A. E. (1996). "Nonlinear optimization procedure for limit analysis." European Journal of Mechanics, A/Solids, 15(3), 487-512. 
Boyd, S. and Vandenberghe, L. (2004). Convex optimization. Cambridge University Press, 1 edition, <www.cambridge.org/9780521833783>.

Červenka, V. and Červenka, J. (2017). ATENA Program Documentation Part 2-2 User's manual for ATENA 3D. Cervenka Consulting.

Drucker, D. C., Prager, W., and Greenberg, H. J. (1952). "Extended limit design theorems for continuous media." Quarterly of Applied Mathematics, 9(4), 381-389.

Ferreira, D. (2020). Diana User Manual, Release 10.4. DIANA FEA, Delft.

Geuzaine, C. and Remacle, J. F. (2009). "Gmsh: A 3-D finite element mesh generator with built-in pre- and post-processing facilities." International Journal for Numerical Methods in Engineering, 79(11), 1309-1331.

Gimeno, C. M. (2017). "A finite element-based approach for the analysis and design of 3D reinforced concrete elements and its application to D-regions." Ph.d. thesis, Universitat Politècnica de València, Valencia, <http://hdl.handle.net/10251/86193>.

Gvozdev, A. (1960). "The determination of the value of the collapse load for statically indeterminate systems undergoing plastic deformation." International Journal of Mechanical Sciences, 1(4), 322-335.

Herfelt, M. A. (2017). "Numerical limit analysis of precast concrete structures - A framework for efficient design and analysis." Ph.d. thesis, Technical University of Denmark (DTU), Kgs. Lyngby, < https://orbit.dtu.dk/en/publications/numerical-limit-analysisof-precast-concrete-structures-a-framewo $>$.

Herfelt, M. A., Krabbenhøft, J., and Krabbenhøft, K. (2019). "Practical Design and Modelling of Precast Concrete Structures." Current Trends in Civil \& Structural Engineering, 3(2), 8-11.

Herfelt, M. A., Poulsen, P. N., and Hoang, L. C. (2018). "Closed form adaptive effectiveness factor for numerical models." The International Federation for Structural Concrete 5th International fib Congress.

Hillerborg, A. (1974). Strimlemetoden. Almqvist \& Wiksell, Stockholm.

Hoang, L. C., Jacobsen, H. J., and Larsen, B. (2012). "Compressive Strength of Reinforced Concrete Disks with Transverse Tension." Bygningsstatiske Meddelelser (Proceedings of the Danish Society for Structural Science and Engineering), 83(2-3), 23-61.

Joergensen, H. B. and Hoang, L. C. (2013). "Tests and limit analysis of loop connections between precast concrete elements loaded in tension." Engineering Structures, 52, $558-569$.

Johansen, K. W. (1943). Brudlinieteorier. Polyteknisk Forening.

Johansen, K. W. (1962). Yield-line theory. Cement and Concrete Association.

Krabbenhøft, K., Lyamin, A., and Sloan, S. (2007a). "Formulation and solution of some plasticity problems as conic programs." International Journal of Solids and Structures, 44(5), 1533-1549.

Krabbenhøft, K., Lyamin, A. V., and Sloan, S. W. (2007b). "Three-dimensional MohrCoulomb limit analysis using semidefinite programming." Communications in $\mathrm{Nu}$ merical Methods in Engineering, 24(11), 1107-1119.

Krabbenhoft, K., Lyamin, A. V., Sloan, S. W., and Wriggers, P. (2007). “An interiorpoint algorithm for elastoplasticity." International Journal for Numerical Methods in Engineering, 69(3), 592-626. 
Larsen, K. P. (2010). "Numerical Limit Analysis of Reinforced Concrete Structures: Computational Modeling with Finite Elements for Lower Bound Limit Analysis of Reinforced Concrete Structures." Ph.d. thesis, Technical University of Denmark (DTU), Kgs. Lyngby, < https://orbit.dtu.dk/en/publications/numerical-limit-analysisof-reinforced-concrete-structures-comput $>$.

Larsen, K. P., Poulsen, P. N., and Otto Nielsen, L. (2009). "Limit analysis of solid reinforced concrete structures." Computational Technologies in Concrete Structures, 154, <https://orbit.dtu.dk/en/publications/limit-analysis-of-solid-reinforcedconcrete-structures $>$.

Lundgren, H. (1949). Cylindrical shells. Danish Technical Press.

Makrodimopoulos, A. and Martin, C. M. (2006). "Lower bound limit analysis of cohesive-frictional materials using second-order cone programming." International Journal for Numerical Methods in Engineering, 66(4), 604-634.

Martin, C. M. and Makrodimopoulos, A. (2008). "Finite-Element Limit Analysis of Mohr-Coulomb Materials in 3D Using Semidefinite Programming." Journal of Engineering Mechanics, 134(4), 339-347.

Mörsch, E. (1922). Der Eisenbetonbau, seine Theorie und Anwendung. Konrad Wittwer, Stuttgart, 5 edition.

MOSEK ApS (2019). MOSEK optimization toolbox for MATLAB manual. Mosek Aps, $<$ https://www.mosek.com/>.

Nielsen, M. P. and Hoang, L. C. (2011). Limit Analysis and Concrete Plasticity. CRC Press, 3rd edition, <https://www.taylorfrancis.com/books/9781439803974>.

Poulsen, P. N. and Damkilde, L. (2000). "Limit state analysis of reinforced concrete plates subjected to in-plane forces." International Journal of Solids and Structures, 37(42), 6011-6029.

Schlaich, J., Schäfer, K., and Jennewein, M. (1987). "Toward a Consistent Design of Structural Concrete." PCI Journal, 32(3), 74-150.

The Mathworks Inc. (2019). "MATLAB R2019b.”, < <ttps://www.mathworks.com/>. Vecchio, F. J. and Selby, R. G. (1991). "Toward Compression-Field Analysis of Reinforced Concrete Solids." ASCE Journal of Structural Engineering, 117(6), 17401758.

Vincent, H., Arquier, M., Bleyer, J., and de Buhan, P. (2018). "Yield design-based numerical analysis of three-dimensional reinforced concrete structures." International Journal for Numerical and Analytical Methods in Geomechanics, 42(18), 2177-2192. 